\title{
Cryptic diversity of the bent-wing bat, Miniopterus schreibersii (Chiroptera: Vespertilionidae), in Asia Minor
}

\author{
Andrzej Furman*1, Tomasz Postawa22, Tunç Öztunç ${ }^{1}$ and Emrah Çoraman¹
}

\begin{abstract}
Background: Two or more species are cryptic, if they are morphologically similar, biologically distinct, and misclassified as a single species. Cryptic species complexes were recently discovered within many bat species and we suspect that the bent-wing bat, Miniopterus schreibersii, found in Europe, northern Africa, and Asia Minor, could also form such a complex. Populations of M. schreibersii decline in most of the European countries and the species is currently listed as Near Threatened in the IUCN Red List. Finding that M. schreibersii is not a single species, but a species complex, would have a considerable impact on its conservation strategies, as the abundance of each component taxon would be much smaller than the one estimated for the nominal species.

Results: Miniopterus schreibersii in Asia Minor consists of two genetically diverged lineages, which are reciprocally monophyletic on three mitochondrial DNA markers, have a diagnostic set of multilocus allele frequencies, and show a marked difference in their population structures. The lineages differ slightly in their size, wing shape, and echolocation call parameters. Although these differences are sufficient to discriminate between the lineages, they are not fully diagnostic in reference to individuals. We suggest that the lineages endured the major Northern Hemisphere glaciations in different glacial refugia and colonized Asia Minor after the last glacial maximum. The lineages are allopatric, which is neither delineated by the presence of geographical barriers nor associated with the specific climatic conditions, and which we link to competitive exclusion.

Conclusions: The distinctions between the lineages comply with most of the criteria required for species delineation imposed by various species concepts. Accordingly, we conclude that M. schreibersii in Asia Minor is represented by two cryptic species. Our results imply that the distributional range of the nominal species is almost exclusively limited to Europe and the coastal zones of Asia Minor. As populations of M. schreibersii seem to be much smaller than currently assumed, conservation strategies regarding this taxon need to be revised. The exact distributional range and the vulnerability of the suggested sister species to M. schreibersii is yet to be assessed.
\end{abstract}

\section{Background}

Two or more species are cryptic, if they are morphologically similar, biologically distinct, and misclassified as a single nominal species [1]. Identification of cryptic species is particularly important in terms of conservation efforts and biodiversity assessments. Species that are apparently in no need of protection may in fact consist of several cryptic and vulnerable component taxa. Similarly, the species richness of some habitats can be considerably

\footnotetext{
* Correspondence: furman@boun.edu.tr

${ }^{1}$ Institute of Environmental Sciences, Boğaziçi University, 34342 Istanbul, Turkey

Full list of author information is available at the end of the article
}

underestimated, lowering their conservation status, because of unrecognized cryptic diversity. Identification of cryptic species often starts with a discovery of diverged matrilineal lineages and the typical sequence differences between intra- and interspecific lineages have been quantified for the cytochrome-b gene (Cytb) [2]. To delineate species, however, the evidence from mitochondrial DNA has to be accompanied by the supportive data from nuclear markers, detailed phenotypic examination, and geographical distribution analyses.

Speciation without morphological divergence is usually linked to selection promoting morphological invariance or to the use of nonvisual mating signals [1]. Thus it is not 
surprising that cryptic diversity is particularly common among bats, which communicate their reproductive signals through acoustic calls [3]. Only over the recent few years DNA sequence analyses revealed the presence of 14 previously unrecognized bat species in the western Palaearctic $[4,5]$.

In this study we investigate the bent-wing bat, Miniopterus schreibersii (Kuhl, 1817). Up to recently, $M$. schreibersii was considered to be a cosmopolitan species with a near-global distribution [6]. A number of molecular studies, however, proved that M. schreibersii was a species complex [7-9] and its presently recognized distributional range is limited to Europe, northern Africa, and Asia Minor [10]. With stable populations in the Balkans and Turkey, and declining in most of the European countries, M. schreibersii is listed as Near Threatened in the IUCN Red List [10]. Yet, even within its constrained distributional range, $M$. schreibersii might not be a single nominal species and, in consequence, its populations might be much smaller than currently thought.

In Asia Minor, M. schreibersii consists of two morphologically similar but genetically diverged matrilineal lineages, which might be indicative of a cryptic species complex. The lineages are reciprocally monophyletic and differ by ca. $9 \%$ on the mitochondrial control region $[11,12]$, ca. $6 \%$ on the NADH dehydrogenase subunit 2 (ND2) and ca. $4 \%$ on Cytb [9]. Calculations based on the ND2 and $C y t b$ data estimate that the lineages split ca. 2.0 to $0.5 \mathrm{Myr} \mathrm{BP}$, implying separation in disjunct Pleistocene glacial refugia. The lineages are allopatric and separated along a zone passing through Central Anatolia [12].

To examine the hypothesis that M. schreibersii in Asia Minor forms a cryptic species complex, we employ a multidisciplinary approach. We use molecular markers to analyze the distribution of the lineages, their population structure and reproductive isolation. We examine morphological and echolocation data to measure ecological divergence of the lineages. Because allopatric populations are per se reproductively isolated, we focus on the putative contact zone between the lineages in Central Anatolia, where the probability of finding mixed colonies or interbreeding individuals is the highest. The sampled roosts are located within different climatic regimes and separated from each other by distances, which $M$. schreibersii is able to cover in its migratory movements $[13,14]$. The location of the roosts allows us to examine the suggestion that the allopatric distribution of the lineages is caused by different climatic preferences [11].

\section{Methods \\ Sampling}

Samples were collected during summer in nine underground sites. The sites were located in the area of about $500 \mathrm{~km}$ by $400 \mathrm{~km}$ in the south of Turkey, which covered parts of the Central Anatolian Plateau and the Mediterranean Sea coast (Figure 1). In each site, ca. 20 bats were caught by a hand net. Bats were sexed, measured, and their right wing photographed. Some individuals had their echolocation calls recorded. Tissue samples were collected from the wing membrane by $3 \mathrm{~mm}$ biopsypunchers as outlined by Worthington Wilmer \& Barratt [15] and stored in 80\% ethyl alcohol. After sampling, bats were immediately released. Our research was approved by the Boğaziçi University Ethics Committee on Animal Research (BÜHADYEK).

\section{Mitochondrial and Microsatellite Markers}

Genomic DNA was extracted from biopsy punches following the Roche High Pure PCR Template Preparation Kit protocol. The mitochondrial control region was amplified with two primers, L15408 and E following the procedures described in Irwin et al. [16] and Wilkinson \& Chapman [17]. PCR products were purified and sequenced with primer $\mathrm{E}$ in Macrogen Inc. Korea. The resulting 152 sequences were edited with Sequencher v. 4.9 (Genecodes Corp., Ann Arbor, MI, USA); the percent of quality bases for each of the sequences varied from 90.2 to $99.8 \%$ and the average quality score was $97.2 \%$. The sequences were aligned using Clustal $\times$ v. 1.8 [18] and inspected visually. The sequences representing unique haplotypes have been deposited to GenBank with the accession numbers [HM044071-HM044103]. Our data were analyzed together with 39 sequences reported previously $[11,12]$.

Microsatellite loci were amplified with ten pairs of primers, Mschreib2, Mschreib4, CH37, CH85, CH87, CHA14, CHB12, CHD2, CHD3, and NCAM following the procedures described in Miller-Butterworth et al. [19], Han et al. [20], and Moore et al. [21]. Four loci, CH85, CHA14, CHD3, and NCAM, were monomorphic and were excluded from further analyses. Microsatellite loci were scored in Macrogen Inc. Korea. To detect the presence of possible errors in our data we used MicroChecker 2.2 [22]. No null alleles, large allelic dropout, or other errors were identified.

\section{Lineage Identification}

We refer to the matrilineal lineages of $M$. schreibersii as M. s. schreibersii (type locality: Kolumbacs cave, Romania; Kuhl, 1817) and M. s. pallidus (type locality: South coast of Caspian Sea, Iran; Thomas, 1907). Our delineation of the lineages is not based on a difference in dorsal coloration, which traditionally was used to distinguish these subspecies but proved to be inconsistent with their genetic identity [12]. Instead, we refer to the similarity of the mitochondrial control region sequences of $M$. schreibersii from Bulgaria (located near the type locality of M. s. schreibersii) to one of the lineages and the 


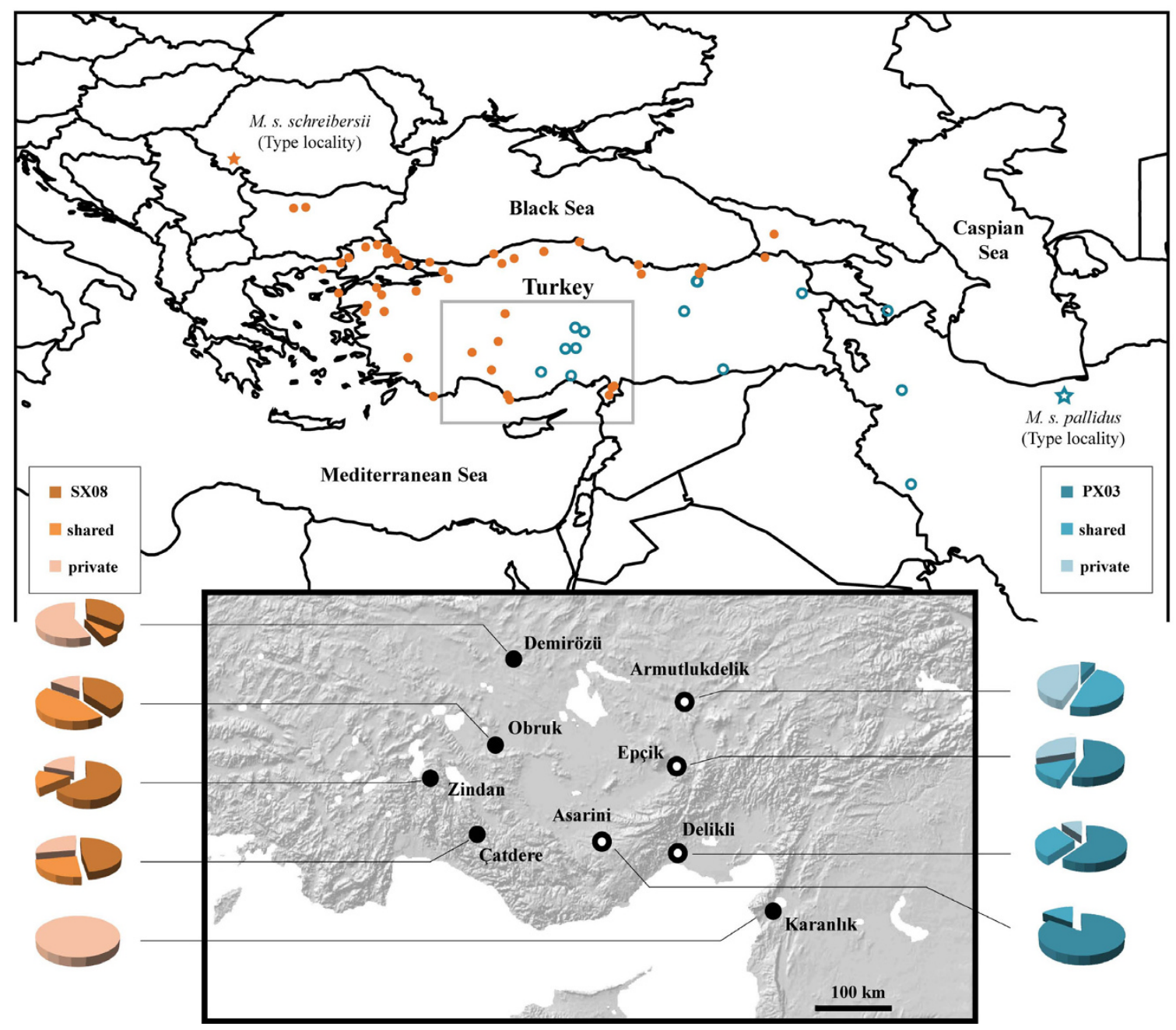

Figure 1 Genetically identified colonies of $M$. s. schreibersii (filled circles) and M. s. pallidus (empty circles) in Thrace and Asia Minor. The underground sites sampled in this study are marked in the insert. Pie charts show distribution of the most common, shared with other colonies, and private haplotypes

sequences of M. schreibersii from Iran and NagornoKarabakh (located near the type locality of M. s. pallidus) to the second one. The lineages can be easily identified by the ten-base fragment, which starts in the beginning of mitochondrial control region (at the seventh position after tRNA-Pro). The fragment 'C-TGTCAAGT' is typical for M. s. schreibersii and the fragment 'TATGCTGGAC' is typical for M. s. pallidus. These fragments have been invariant in all sequences of the mitochondrial control region examined by us up to now.

\section{Mitochondrial and Nuclear Data Analyses}

DNA polymorphism of the mitochondrial control region was assessed by nucleotide diversity and haplotype diversity. Genetic divergence was measured by the average number of pairwise nucleotide differences and the average number of nucleotide substitutions per site with the
Jukes and Cantor correction (JC) [23,24]. The relevant statistics were computed with DnaSP v. 5.00.07 [25] and Arlequin 3.11 [26]. We used the JC estimate, because the number of nucleotide substitutions per site was less than 0.1 , in which case all correction methods calculate about the same distances as JC for closely related sequences [27]. Genetic diversity in the microsatellite data was evaluated by the mean alleles number and the proportion of heterozygotes; both calculated with GeneClass2 [28]. GeneClass2 was also used to implement an assignment test with Bayesian computational criteria [29].

Population genetic structure was investigated by analysis of molecular variance (AMOVA) with $F$ (microsatellites) or $\Phi$ statistics (mtDNA control region); significance of the fixation indices was assessed with 50000 permutations with Arlequin v. 3.11. Correlations between genetic divergences and geographic distances were analyzed by 
plotting pairwise Rousset's distance $\left(\Phi_{\mathrm{ST}} /\left[1-\Phi_{\mathrm{ST}}\right]\right.$ or $F_{\mathrm{ST}} /$ $\left.\left[1-F_{\mathrm{ST}}\right]\right)$ against the logarithm of geographical distance [30]. Statistical significance of correlations was assessed by a Mantel test with 10,000 randomizations as implemented in IBDWS v. 3.15 [31]. Genealogical relationships among haplotypes based on the mitochondrial data were estimated by a statistical parsimony network using 95\% connection limit [32] with TCS v. 1.21 [33].

Demographic history was inferred from a mismatch distribution analysis [34] and raggedness statistics [35]. The models' goodness of fit and the population expansion time parameters $(\tau)$ were assessed with 10,000 bootstrap replicates using Arlequin v. 3.11. Approximate time to population expansion events was estimated with the assumption of a mutation rate of $20 \%$ per Myr [36] and a generation time of five years [14]. Although the assumed mutation rate was calibrated for D-loop in Nyctalus noctula, it was also used to estimate population expansion times for M. schreibersii $[11,12,14]$. Additionally, the approximation of $20 \%$ per Myr represents the average mutation rate estimated for other mammals, which varies from $10 \%$ per Myr for house mouse [37], through 12-17\% per Myr for humans [38], to 30\% per Myr for steppe bison [39].

Phylogenetic trees were constructed with Neighbour Joining method (NJ) [40]. We used the NJ method as it can easily accommodate short internal branches and is recommended for constructing phylogenetic trees of closely related species [41]. For the mitochondrial data, the tree was generated with PAUP* v. 4.0b10 [42]. In the mitochondrial control region analysis we included four sequences from Bulgaria [GenBank: EU332359, EU332360, EU332369, and EU332378], two sequences from Iran [GenBank: FJ028638 and FJ028640], and two sequences from Nagorno-Karabakh [GenBank: FJ028634 and FJ028635], which represent samples collected near the type localities of $M$. s. schreibersii and M. s. pallidus $[11,12]$. For the microsatellite data, the tree was constructed with Poptree (N. Takezaki, Max-Planck Institut für Biologie, Tuebingen, Germany) using the modified Cavalli-Sforza distance [43]. The nodal support was assessed from 10,000 nonparametric bootstrap replicates.

\section{Morphometric and Echolocation Data}

Morphometric measurements consisted of body mass (precision: $\pm 0.5 \mathrm{~g}$ ) and wing measurements (precision \pm $0.1 \mathrm{~mm})$. The wing measurements included forearm length (FA) measured on captured bats and phalanges length of the third, fourth, and fifth digit measured on wing photographs. Juvenile bats were excluded from analyses. We used wing measurements to compute tip index, aspect ratio index, and area index as described in Findley et al. [44]. Morphological wing data were ana- lyzed with a t-test and a stepwise discriminant function analysis.

Echolocation calls were recorded in a flight tent $(5 \mathrm{~m} \times$ $1.5 \mathrm{~m} \times 1.5 \mathrm{~m}$ ) and/or from hand-released bats with a time expansion bat detector (D240x, Pettersson Elektronik AB, Uppsala, Sweden) using a sampling frequency of $44.1 \mathrm{kHz}$ with $16 \mathrm{bits} / \mathrm{sample}$. Only the search-phase calls were recorded. The calls, after frequency transformation, were stored on a digital sound recorder (Edirol R09, Roland Corporation). The recordings were analyzed with BatSound v. 3.31 (Pettersson Elektronik AB, Uppsala, Sweden). The analyzed echolocation call parameters included starting frequency, terminal frequency, peak frequency, band width (a difference between starting and terminal frequencies), and call duration. For each bat, the echolocation call parameters were averaged from the five best quality recordings. The echolocation parameters were analyzed by a t-test and a stepwise discriminant function analysis.

\section{Results}

Distribution

Miniopterus s. schreibersii and M. s. pallidus were strictly allopatric within their putative contact zone. The colonies of both lineages were found on the Central Anatolian Plateau with the semiarid steppe climate and on the Mediterranean Sea coast with the wet Mediterranean climate. Similarly, there was no distinction in the altitude of the roost occupied by $M$. s. schreibersii or M. s. pallidus, which in both cases were located on elevations varying from ca. $200 \mathrm{~m}$ to $1600 \mathrm{~m}$ Above Sea Level.

\section{Mitochondrial and Microsatellite Data}

The 191 mitochondrial control region sequences (110 M. s. schreibersii and 81 M. s. pallidus), were 418 or 419 bp long. The sequences of $M$. s. pallidus were longer because of a base insertion at the ninth position after Pro-tRNA gene. The sequences yielded 43 unique haplotypes: 27 in M. s. schreibersii and 16 in M. s. pallidus (Additional file 1). The average haplotype diversity within M. s. schreibersii was $0.84 \pm 0.03$ and $0.71 \pm 0.05$ within $M$. s. pallidus; the average nucleotide diversities (JC) were $0.0067 \pm$ 0.0004 and $0.0036 \pm 0.0004$, respectively. There were 19 fixed differences between M. s. schreibersii and M. s. pallidus, 25 substitutions were polymorphic in $M . s$. schreibersii, but monomorphic in M. s. pallidus, 9 substitutions were polymorphic in $M$. s. pallidus, but monomorphic in $M$. s. schreibersii, and 4 substitutions were shared. The average number of nucleotide differences was 29.77 and the average number of nucleotide substitutions per site (JC) between M. s. schreibersii and M. s. pallidus was $0.075 \pm 0.005$.

The six polymorphic microsatellite loci scored for 174 individuals (95 M. s. schreibersii and 79 M. s. pallidus) 
yielded 57 distinct alleles. The mean allele richness was $6.33 \pm 3.67$ in M. s. schreibersii and $8.00 \pm 3.23$ in M. s. pallidus; the mean heterozygosities were $0.42 \pm 0.31$ and $0.63 \pm 0.23$, respectively. When only a single locus was analyzed, an assignment test with the threshold of scores set to 0.05 correctly identified from $80 \%$ (Mschreib4) to 98\% (CH37) of individuals as M. s. schreibersii or M. s. pallidus. With all six microsatellite loci, the test correctly identified $100 \%$ of individuals (quality index $=99.92 \%$ ), indicating that each lineage had a diagnostic set of multilocus allele frequencies.

The unrooted NJ tree constructed from microsatellite data clearly separated colonies of M. s. schreibersii and $M$. s. pallidus with $100 \%$ bootstrap support (Figure 2). Similarly, the tree based on the mitochondrial data also recovered two distinct lineages of M. s. schreibersii and M. s. pallidus with $100 \%$ bootstrap support (Figure 2). The $M$. s. schreibersii clade included the sequences from Bulgaria and the M. s. pallidus clade included the sequences from Iran and Nagorno-Karabakh.

\section{Population Genetic Structure}

The average haplotype diversity within the colonies of $M$. s. schreibersii varied from 0.58 to 0.77 and the average nucleotide diversity varied from 0.0035 to 0.0069 (Table 1). The colonies showed only a moderate genetic differentiation with $74 \%$ of the molecular variance explained by within colonies diversity $\left(\Phi_{\mathrm{ST}}=0.257, p<0.001\right)$. Pair-

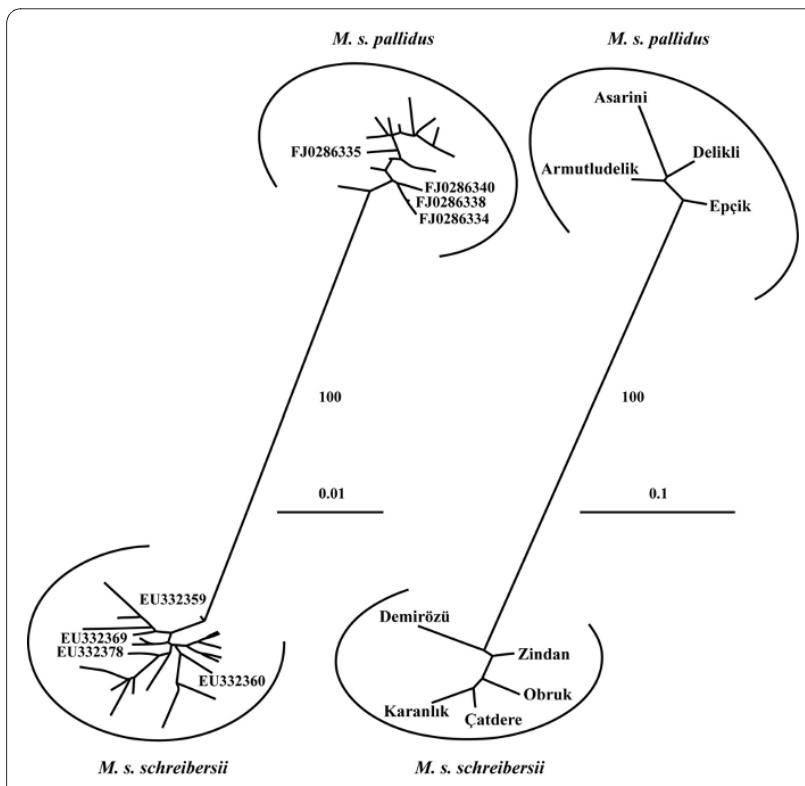

Figure 2 Phylogenetic $N J$ trees constructed from the mtDNA (left) and microsatellite (right) data. Accession mark GenBank sequences of M. s. schreibersii from Bulgaria (EU332359, EU332360, EU332369, and EU332378) and GenBank sequences of M. s. pallidus from Iran (FJ028638 and FJ028640) and Nagorno-Karabakh (FJ028634 and $\underline{\mathrm{FJ} 028635}$ ). The nodal support is shown only for the main lineages. wise fixation indices were larger between Karanllk and other colonies ( 0.352 to 0.478$)$ than between the remaining pairs $(\leq 0.226)$ (Table 2). Rousset's distances calculated for pairs of the M. s. schreibersii colonies strongly correlated with the logarithm of geographic distances between them $(r=0.91 ; p<0.001)$. Within the colonies of M. s. pallidus, the average haplotype diversity varied more and the average nucleotide diversity was lower $(0.28$ to 0.84 and 0.0014 to 0.0041 , respectively). The colonies of M. s. pallidus also revealed a much weaker population structure; $92 \%$ of the molecular variance was assigned to within colonies diversity $\left(\Phi_{\mathrm{ST}}=0.081, p=0.003\right)$. All, but one, fixation indices between the colonies of M. s. palli$d u s$ were smaller than 0.1 . The only exception was the Armutludelik-Asarini pair; the two farthest colonies $\left(\Phi_{\mathrm{ST}}\right.$ $=0.257$ ). Although there was a considerable correlation between Rousset's distances and the logarithm of geographic separation between pairs of the M. s. pallidus colonies, the relation was not significant $(r=0.74 ; p=0.084)$.

The mean number of microsatellite alleles within the colonies of M. s. schreibersii varied from 3.33 to 4.50 and the proportion of heterozygotes ranged from 0.38 to 0.50 (Table 1 ). There was only a slight genetic differentiation among the colonies of M. s. schreibersii and $97 \%$ of the molecular variation was explained by within colony diversity $\left(F_{\mathrm{ST}}=0.027, p<0.001\right)$. Within the colonies of $M$. s. pallidus both the mean number of alleles, and the proportion of heterozygotes were higher than in $M$. $s$. schreibersii: 5.50 to 6.50 and 0.58 to 0.67 , respectively. The colonies of M. s. pallidus did not show any indications of gene flow restrictions and almost $100 \%$ of molecular variance was explained by within colony diversity $\left(F_{\mathrm{ST}}=0.002, p=0.307\right)$. Pairwise differences $\left(F_{\mathrm{ST}}\right)$ between the colonies of $M$. s. schreibersii were very small, signifying only weak population structure (Table 2). Rousset's distances calculated for pairs of the colonies of M. s. schreibersii strongly correlated with the logarithm of geographic distances between them $(r=0.69 ; p=0.020)$. The colonies of $M$. s. pallidus showed no between-colony differentiations as indicated by pairwise fixation indices being about one order of magnitude smaller than those observed in M. s. schreibersii. Similarly, there was no correlation between Rousset's distances and the logarithm of geographic distances in M. s. pallidus $(r=-0.06 ; p=$ $0.627)$.

\section{Statistical Parsimony Network}

A statistical parsimony network of $M$. s. schreibersii was built around the most common haplotype SX08 (38 individuals; 35\%; absent in Karanlı) (Figure 3). Because of its central position in the network, high number of connections, and a spacious distribution, SX08 was accepted to be the most plausible candidate for the ancestral haplotype of M. s. schreibersii. Although SX03 and SX16 also 
Table 1: Genetic diversity within the colonies of $M$. s. schreibersii and $M$. s. pallidus based on $418 / 419$ bp of the mtDNA control region sequences and six microsatellite loci.

\begin{tabular}{|c|c|c|c|c|c|c|c|c|}
\hline & \multirow[b]{2}{*}{ Site } & \multicolumn{4}{|c|}{ mtDNA } & \multicolumn{3}{|c|}{ microsatellites } \\
\hline & & $\mathbf{N}$ & $\mathbf{h}$ & Hd & $\pi(J C)$ & $\mathbf{N}$ & A & HE \\
\hline \multirow[t]{5}{*}{ M. s. schreibersii } & Çatdere & 25 & 10 & 0.77 & 0.0069 & 11 & 3.333 & 0.379 \\
\hline & Demirözü & 14 & 4 & 0.66 & 0.0059 & 14 & 4.333 & 0.495 \\
\hline & Karanlık & 31 & 9 & 0.73 & 0.0035 & 30 & 4.000 & 0.426 \\
\hline & Obruk & 20 & 6 & 0.71 & 0.0060 & 20 & 4.333 & 0.408 \\
\hline & Zindan & 20 & 6 & 0.58 & 0.0047 & 20 & 4.500 & 0.375 \\
\hline \multirow[t]{4}{*}{ M. s. pallidus } & Armutludelik & 21 & 8 & 0.84 & 0.0041 & 20 & 5.500 & 0.581 \\
\hline & Asarini & 20 & 4 & 0.28 & 0.0014 & 20 & 6.333 & 0.611 \\
\hline & Delikli & 20 & 6 & 0.63 & 0.0039 & 20 & 5.833 & 0.644 \\
\hline & Epçik & 20 & 10 & 0.71 & 0.0040 & 19 & 6.500 & 0.671 \\
\hline
\end{tabular}

$\mathrm{N}=$ number of individuals sampled, $\mathrm{h}=$ number of observed haplotypes, $H_{\mathrm{d}}=$ haplotype diversity, $\pi(J C)=$ nucleotide diversity with the Jukes and Cantor correction, $\mathrm{A}=$ mean alleles number, $H_{\mathrm{E}}=$ proportion of heterozygotes.

had many connections to other haplotypes, SX03 had a marginal position in the network and SX16 was spatially constrained to Karanlık. Additionally, SX16 was linked to other colonies almost entirely through 'absent-haplotype' connections. A statistical parsimony network of M. s. pallidus was constructed around the central haplotype PX12 (9 individuals; 10\%; absent in Delikli). Although this haplotype was neither the most common nor the most widespread, its central position and connections to six other haplotypes made it a likely candidate to be the ancestral haplotype within the M. s. pallidus colonies. There was a pronounced southward decrease in haplotype diversity within the colonies of $M$. s. pallidus: the most common hyplotype, PX03, was present in $7 \%$ of individuals in Armutludelik, 55\% in Epçik, 60\% in Delikli, and 85\% in Asarini (Figure 1). Correspondingly, frequencies of private haplotypes were $45 \%, 30 \%, 10 \%$, and $0 \%$, respectively.

\section{Mismatch Distribution}

The mismatch distribution analysis suggested population expansion models for demographic histories of $M$. $s$. schreibersii and M. s. pallidus. Harpending's raggedness indices were $r_{\text {M.s.s. }}=0.065$ and $r_{\text {M.s.p. }}=0.044$. In the demographic expansion models, the probabilities of observing

Table 2: Pairwise fixation indices between the colonies of $M$. s. schreibersii and $M$. s. pallidus derived from the mtDNA data ( $\Phi_{\mathrm{ST}}$; below diagonal) and from the microsatellite data $\left(F_{\mathrm{ST}} ;\right.$ above diagonal).

\begin{tabular}{llllll}
\hline M. s. schreibersii & Çatdere & Demirözü & Karanlık & Obruk & Zindan \\
\hline Çatdere & - & $0.03330^{(*)}$ & 0.01621 & 0.00207 & -0.01506 \\
Demirözü & $0.15715^{(*)}$ & - & $0.04450^{(*)}$ & $0.02673^{(*)}$ & $0.02648^{(*)}$ \\
Karanlık & $0.36601^{(*)}$ & $0.35221^{(*)}$ & - & $0.02196^{(*)}$ & $0.05238^{(*)}$ \\
Obruk & 0.07481 & 0.09962 & $0.35343^{(*)}$ & - & 0.01712 \\
Zindan & -0.00403 & $0.22607^{(*)}$ & $0.47821^{(*)}$ & $0.12523^{(*)}$ & - \\
\hline M. s.pallidus & Armutludelik & Asarini & Delikli & Epçik & \\
\hline Armutludelik & - & & & 0.00590 & -0.00033 \\
Asarini & $0.25711^{(*)}$ & 0.01441 & 0.00059 & -0.00452 \\
Delikli & $0.07295^{*}$ & - & -0.00127 & - \\
Epçik & $0.08666^{(*)}$ & 0.03930 & - & -0.01831 & \\
\hline Starsindicatevalues & 0.01081 & &
\end{tabular}

Stars indicate values significant at the 0.05 level. 


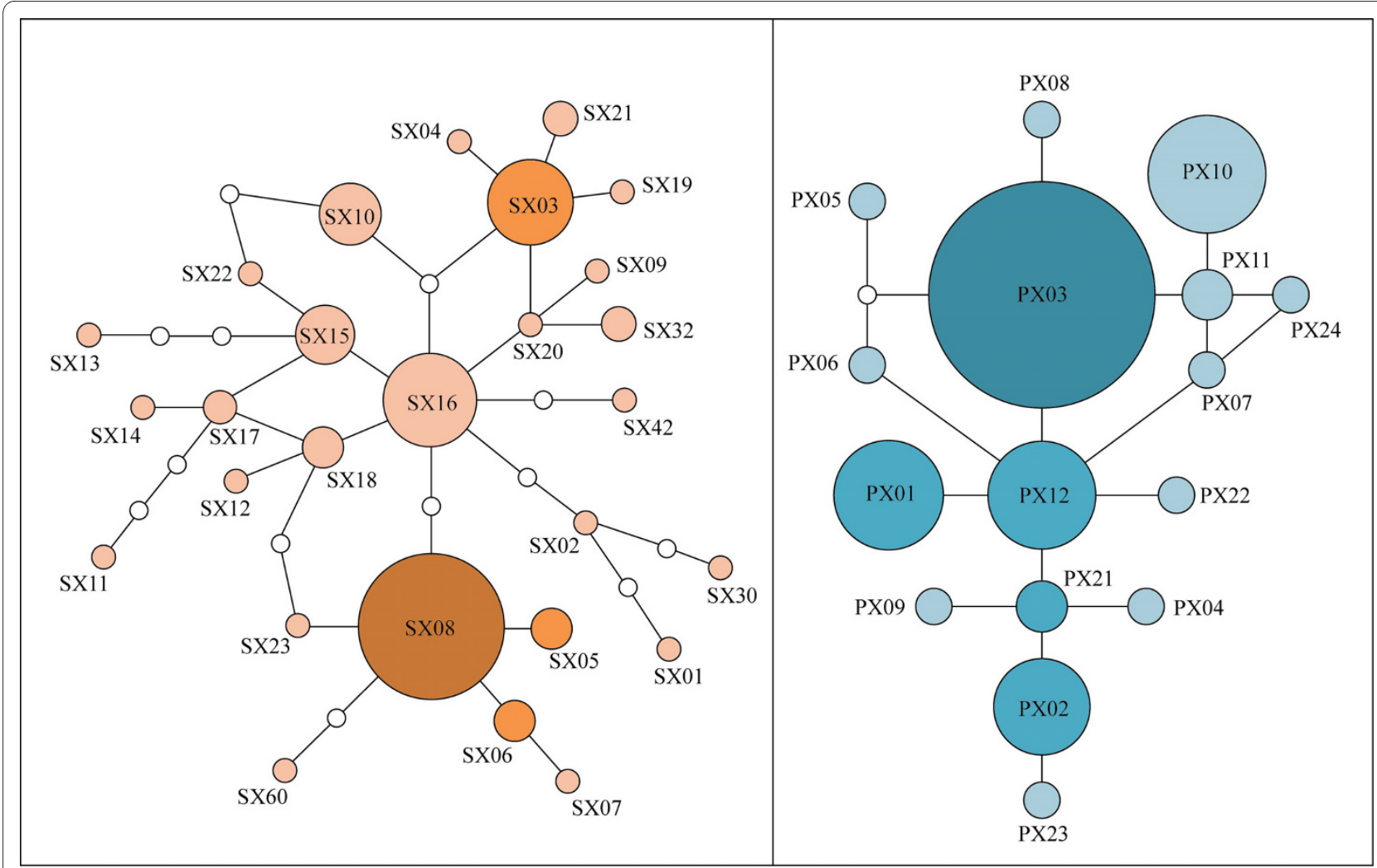

Figure 3 Statistical parsimony network: genealogical relationships among haplotypes of $M$. s. schreibersii (left) and $M$. s. pallidus (right). The most common, shared with other colonies, and private haplotypes are shaded in the same way as in Figure 1. Small, empty circles indicate intermediate haplotypes that were not present in the sample. Lines in the network represent single mutational changes. Sizes are proportional to the number of individuals.

distributions with higher raggedness under a null hypothesis of population expansion were $p_{\text {M.s.s. }}=0.11$ and $p_{\text {M.s.p. }}$. $=0.73$. The sums of squared differences between the observed and expected distributions were no significant $\left(p_{\text {M.s.s. }}=0.15 ; p_{\text {M.s.p. }}=0.45\right)$. The estimated time of the demographic expansion was $21.5 \mathrm{kyr}$ BP (95\% C. I.: 36.5 to $6.6 \mathrm{kyr} \mathrm{BP})$ for M. s. schreibersii $(\tau=3.6)$ and $13.7 \mathrm{kyr}$ BP (95\% C. I.: 29.2 to 0.4 kyr BP) for M. s. pallidus ( $\tau=$ 2.3).

\section{Morphometrics}

The body mass was taken in 133 individuals (73 M. s. schreibersii and 60 M. s. pallidus). Miniopterus s. schreibersii was a lighter bat than M. s. pallidus (13.0 \pm $1.1 \mathrm{~g}$ and $14.7 \pm 1.2 \mathrm{~g}$, respectively); the difference being significant at the 0.001 level. There were not any significant differences in weight between sexes within each group.

The wing measurements were analyzed for 150 individuals (78 M. s. schreibersii and 72 M. s. pallidus). The average forearm length of $M$. s. schreibersii (46 females and 32 males) was $45.7 \pm 0.6 \mathrm{~mm}$ and that of M. s. pallidus (22 females and 50 males) was $46.8 \pm 0.7 \mathrm{~mm}$, the difference being significant at the 0.001 level. The observed difference in forearm length was almost exactly the same as the one based on much wider distributional sampling [12]. There was a slight sexual dimorphism within both lineages; females tended to have longer forearms than males, but the differences were not statistically significant. Forearm lengths of $M$. s. schreibersii and M. s. palli$d u s$ were normally distributed. Except for the $1^{\text {st }}$ phalanx of the $3^{\text {rd }}$ digit (3c), the average lengths of phalanges (Table 3 ) were consistently longer in M. s. pallidus ( $p<$ $0.001)$. The 3c phalanx length was approximately the same in both groups $(p=0.323)$. All wing indices differed significantly at the 0.001 level (tip index: $\mathrm{TI}_{\text {M.s.s. }}=1.99 \pm$ 0.03 and $\mathrm{TI}_{\text {M.s.p. }}=1.96 \pm 0.03$; aspect ratio index: $\mathrm{AR}_{\text {M.s.s. }}=$ $2.53 \pm 0.06$ and $\mathrm{AR}_{\text {M.s.p. }}=2.45 \pm 0.04$; area index $\mathrm{AI}_{\text {M.s.s. }}=$ $14756 \pm 554$ and $\mathrm{AI}_{\text {M.s.p. }}=15567 \pm 481$ ). Stepwise discriminant analysis, using the phalanges and forearm measurements, found a canonical function that included three variables: forearm length, length of the $2^{\text {nd }}$ phalanx of the $5^{\text {th }}$ digit, and length of the metacarpal of the $4^{\text {th }}$ digit; the discriminant function correctly assigned the group membership in $85 \%$ of the individuals. 
Table 3: Length of the phalanges of the $3^{\text {rd }}, 4^{\text {th }}$, and $5^{\text {th }}$ digit (a: the metacarpal; b: the $2^{\text {nd }}$ phalanx; c: the $1^{\text {st }}$ phalanx) ([mm]; mean \pm SD).

\begin{tabular}{|c|c|c|c|c|c|c|c|c|c|}
\hline & $3 a$ & $3 \mathbf{b}$ & $3 c$ & $4 a$ & $4 b$ & $4 c$ & $5 a$ & $5 b$ & $5 c$ \\
\hline M.s.s. & $\begin{array}{l}42.4 \pm \\
0.7\end{array}$ & $\begin{array}{l}10.8 \pm \\
0.3\end{array}$ & $\begin{array}{l}37.4 \pm \\
1.0\end{array}$ & $\begin{array}{l}41.2 \pm \\
0.7\end{array}$ & $\begin{array}{l}8.80 \pm \\
0.3\end{array}$ & $\begin{array}{l}16.9 \pm \\
0.6\end{array}$ & $\begin{array}{l}37.5 \pm \\
0.9\end{array}$ & $8.4 \pm 0.9$ & $8.2 \pm 0.8$ \\
\hline M. s.p. & $\begin{array}{l}43.0 \pm \\
0.7\end{array}$ & $\begin{array}{l}11.2 \pm \\
0.4\end{array}$ & $\begin{array}{l}37.2 \pm \\
1.0\end{array}$ & $\begin{array}{l}42.0 \pm \\
0.7\end{array}$ & $9.0 \pm 0.3$ & $\begin{array}{l}17.7 \pm \\
0.7\end{array}$ & $\begin{array}{l}38.2 \pm \\
0.7\end{array}$ & $9.3 \pm 0.5$ & $8.9 \pm 0.6$ \\
\hline
\end{tabular}

\section{Echolocation}

The echolocation call parameters were analyzed in 33 individuals (13 M. s. schreibersii and 20 M. s. pallidus). The starting frequency, the peak frequency, and the band width differed significantly between the lineages at the 0.001 level (Table 4). The terminal frequency and the call duration were similar in both groups $\left(p_{\text {duration }}=0.294\right.$ and $p_{\text {terminal }}=0.270$ ). A stepwise discriminant analysis found a canonical function that included two variables, the starting frequency and the call duration; the discriminant function assigned $88 \%$ of the individuals to the correct groups.

\section{Discussion}

Cryptic species complexes, in which the component taxa have not diverged morphologically too much, are very difficult to identify and their discovery is frequently a matter of chance. In a recent study investigating the contribution of the 28 Iberian bat species to the cryptic diversity in Europe, almost $20 \%$ of the Iberian bats showed considerable mitochondrial discontinuities either within the Iberian or between Iberian and other European samples [4]. One of the very few species, which in that study proved to be genetically very homogenous, was M. schreibersii. In Asia Minor, however, M. schreibersii consists of two genetic lineages, which differ considerably on three mitochondrial markers (Cytb, ND2, and the control region) and which have the diagnostic set of multilocus allele frequencies $[9,12$, this study]. The mitochondrial differentiation between the $M$. schreibersii lineages is particularly striking in the light of the similar- ity observed within each of them; there is only a shallow differentiation in the control region and almost no differentiation in Cytb between colonies of M. s. schreibersii sampled in Anatolia, Iberia, or Maghreb [4,9,45]. A similar homogeneity is observed within M. s. pallidus [9].

\section{Population Genetic Structure}

The extant colonies of M. s. schreibersii and M. s. pallidus in Anatolia show visible differences in their population genetic structure. The colonies of $M$. s. schreibersii reveal the moderate differentiation in the control region sequences accompanied by the very strong correlation between the genetic and geographic distances. At the microsatellite level, the differentiation is weak but the association between the genetic and geographic distances is still strong. The results are in concordance with the ones reported for $M$. s. schreibersii from Portugal, which were linked to female philopatry and a mainly malemediated gene flow [14]. On the other hand, the colonies of $M$. s. pallidus show only a weak differentiation in the control region sequences and no significant correlation between the genetic differentiation and geographic distance. The latter outcome, however, should be taken with a caution as the small number of colonies could profoundly affect the significance of the correlation. At the microsatellite level, the colonies of $M$. s. pallidus do not reveal any indications of population structuring. Both the differentiation between the colonies and the association between the genetic and geographic distances are virtually zero, suggesting no constrains imposed on gene flow.

The colonies of M. s. schreibersii in Karanllk and M. s. pallidus in Asarini and Delikli deserve a special attention

Table 4: Echolocation calls parameters: SF = starting frequency, $T F=$ terminal frequency, $\mathrm{PF}=\mathrm{starting}$ frequency, $\mathrm{BW}=$ band width, $C D=$ call duration.

\begin{tabular}{|c|c|c|c|c|c|c|}
\hline & & SF [kHz] & TF [kHz] & PF [kHz] & BW [kHz] & $\mathrm{CD}$ [ms] \\
\hline \multirow{2}{*}{$\begin{array}{l}\text { M. s. } \\
\text { schreibersii }\end{array}$} & Mean $\pm S D$ & $111.1 \pm 4.4$ & $48.6 \pm 1.5$ & $58.8 \pm 1.7$ & $62.7 \pm 4.9$ & $3.4 \pm 0.5$ \\
\hline & Range & $104.8-118.3$ & $46.3-52.0$ & $56.4-61.7$ & $56.5-71.8$ & $2.8-4.6$ \\
\hline \multirow[t]{2}{*}{ M. s. pallidus } & Mean $\pm S D$ & $95.9 \pm 8.2$ & $48.1 \pm 0.9$ & $56.1 \pm 1.5$ & $47.8 \pm 8.5$ & $3.6 \pm 0.8$ \\
\hline & Range & $72.7-107.2$ & $46.4-49.5$ & $53.1-58.5$ & $25.3-61.0$ & $2.3-5.6$ \\
\hline
\end{tabular}


(Figure 1). The former one is distanced from the other colonies of M. s. schreibersii by about 400-500 km and interposed by the colonies in Asarini and Delikli, which mark the south-most border of the Anatolian distribution of M. s. pallidus. The colony in Karanlik accommodates only private haplotypes, a signature of an isolated population. Although the intermediate haplotypes connecting Karanlık to other colonies are mostly missing, Karanlık's haplotypes occupy the central position in the statistical parsimony network, suggesting a relatively recent demographic history shared with the other $M$. s. schreibersii colonies. On the other hand, the colony in Asarini accommodates only $10 \%$ of private haplotypes and Delikli accommodates none. The pattern of decrease in frequency of private haplotypes from the Central Anatolian Plateau towards the Mediterranean, complemented by the increase in frequency of one haplotype, PX03, is observed in all of the M. s. pallidus colonies. This pattern may indicate the recent southwards expansion from Central Anatolia. Such expansion would include many founder/bottleneck episodes and the successful vanguards would dominate the new population genome, a chain of events inevitably leading to a loss of haplotype diversity $[46,47]$.

\section{Morphology}

Morphologically, M. s. schreibersii is a smaller bat than $M$. s. pallidus (shorter forearm length and lower wing area index) and has narrower and more elongated wings (higher tip and aspect ratio indices). There are also significant differences in echolocation call parameters between the lineages. Although, in principle, higher aspect ratio and tip indices are associated with swifter flight [44] and variations in echolocation calls are related to utilization of diverse foraging habitats [48], the differences found between M. s. schreibersii and M. s. pallidus are relatively small and the ranges are overlapping. Indeed, even though wing morphology and echolocation call parameters are sufficient to discriminate between the lineages, they are not fully diagnostic in reference to a single individual. In consequence, the observed dissimilarities can probably only minutely affect the foraging performance of bats, resulting in a considerable overlap in their ecological niches and leaving them prone to an intensive interlineage competition. A similar situation is found in European Plecotus species: echolocation signals of $P$. macrobullaris are more similar to allopatrically occurring $P$. austriacus than to co-occurring $P$. auritus, although $P$. macrobullaris is genetically closer related to $P$. auritus $[49,50]$. In fact, morphological similarity is typical for all species historically comprising the M. schreibersii complex [7] and may indicate intrinsic deficiency in phenotypic plasticity within these taxa or selection promoting morphological stasis.

\section{Historical Scenario}

According to the estimates based on the Cytb and ND2 data, M. s. schreibersii and M. s. pallidus diverged after the onset of the major Northern Hemisphere glaciations in the Lower or Middle Pleistocene [9]. The lineages probably remained isolated until the end of the last glacial maximum. The best estimates imply that $M$. s. schreibersii survived the major glaciations in a single glacial refugium in the north-western Anatolia/Balkans and rapidly colonized Europe ca. 15 kyr BP [51]. Asia Minor was probably colonized earlier by M. s. schreibersii and a few colonies might have survived the last glacial maximum in one of the south Anatolian refugia, located along the Mediterranean Sea coast. The latter hypothesis is supported by the earlier expansion time estimated here for the south Anatolian population (ca. $21 \mathrm{kyr} \mathrm{BP}$ ) than for the European expansion. Considerably less can be conjectured about the history M. s. pallidus; it probably survived the major glaciations in refugia located somewhere on the southern coast of the Caspian Sea, the eastern part of the Caucasian refugium. It is unlikely that $M$. s. pallidus endured the glacial periods in Colchis, a western part of the Caucasian refugium, as this region is presently occupied by M. s. schreibersii and it is dubious that the former replaced the latter. Miniopterus s. pallidus possibly expanded to Anatolia after the climatic change that followed the end of the last glacial maximum, ca. $13 \mathrm{kyr}$ BP. The late colonization of the Central Anatolian Plateau may be a result of the high altitude of the region (and more severe climatic conditions) and the scarcity of suitable underground habitats. The lineages came to contact in the Central Anatolia. Probably, when they met, M. $s$. schreibersii had already established colonies on the Central Anatolian Plateau and along the Mediterranean Sea coast.

\section{Distribution}

Spatial separation of M. s. schreibersii and M. s. pallidus is neither delineated by the presence of geographical barriers nor associated with the specific climatic conditions. Although most of the known colonies of M. s. schreibersii are found in coastal, low altitude locations with the wet Mediterranean or Black Sea climate $[11,12]$, the colonies in Obruk and Demirözü are located in the Central Anatolian Plateau with the semiarid steppe climate on the altitudes of ca. $1600 \mathrm{~m}$ and $900 \mathrm{~m}$, respectively. Conversely, even though $M$. s. pallidus mainly occupies semiarid regions of higher altitude, the colonies in Asarini and Delikli are located near, or on, the Mediterranean Sea coast exhibiting the wet Mediterranean climate, on the altitudes of ca. $1600 \mathrm{~m}$ and $200 \mathrm{~m}$. Therefore, it is plausible to conclude that both lineages are fully capable of utilizing both inland and coastal habitats, and have similar ecological niches. 
We suggest that in its southwards expansion, $M$. s. pallidus possibly replaced some colonies of $M$. s. schreibersii. The replacement rather than a sympatric coexistence of the lineages could be caused by the morphological similarities between the lineages and resulting competitive exclusion [52]. Accordingly, we presume that the extant geographical distributions of M. s. schreibersii and M. s. pallidus are the result of the historical and ongoing expansion events, and interlineage competition rather than the outcome of climatic preferences as suggested by Bilgin et al. [11].

\section{Taxonomical Implications}

In the light of available evidence, $M$. s. schreibersii and $M$. s. pallidus form two separately evolving lineages, making them potentially different species [53]. The lineages are reciprocally monophyletic on the three mitochondrial DNA markers $[9,12]$, have the diagnostic set of multilocus allele frequencies and their common ancestor is apparently extinct, satisfying the main criteria imposed by the phylogenetic species concept $[54,55]$. The genetic differentiation between lineages in the mitochondrial cytochrome-b gene is within the range recognized for sister taxa by the genetic species concept [2]. The lineages are also phenetically distinguishable, in line with the phenetic species concept $[56,57]$. Furthermore, the lineages seem to be reproductively isolated, as implied by the divergence on nuclear microsatellites in the putative contact zone, despite the lack of any obvious geographic barriers, partly fulfilling requirements of the biological species concept $[58,59]$.

\section{Conclusions}

The distinctions between M. s. pallidus and M. s. schreibersii seem to be sufficient to recognize $M$. schreibersii in Asia Minor as a cryptic species complex and to grant M. s. pallidus a full species status, a sister taxon to M. schreibersii. Still, we do not know about the mechanism of reproductive isolation between $M$. $s$. schreibersii and M. s. pallidus, which probably includes a difference in mating calls, and we know very little about their ecological divergence. Further and more extensive studies are needed to clarify these points.

The results of this study are particularly important for the conservation of the M. schreibersii. The distributional range of the nominal species, $M$. s. schreibersii, is mainly limited to Europe and the coastal zones of Asia Minor; an area much smaller than currently recognized by the IUCN Red List of Threatened Species [10]. The rate of population decline of $M$. schreibersii, including stable populations in the Balkans and Turkey, is estimated to be approaching 30\% [10]. However, taking into consideration that many Turkish populations represent $M$. s. palli$d u s$, the decline rate of $M$. s. schreibersii might already be much higher than estimated by the IUCN Red List. Accordingly, a thoughtful revision of all conservation strategies regarding $M$. s. schreibersii might be crucial to preserve this taxon. The presence of M. s. pallidus in Asia Minor requires a protection program, which would estimate abundance of its current populations, identify possible threats, and assess its conservation status.

Finally, the case of $M$. schreibersii may be indicative for other bat species, which persisted through the major glaciations in the Anatolian refugia. Here, potential candidates are Rhinolophus euryale and R. ferrumequinum. Both species consist of considerably diverged matrilineal lineages $[60,61]$ and each of them could be, in principle, a cryptic species complex.

\section{Additional material}

Additional file $\mathbf{1}$ List of haplotypes analyzed in this study.

\section{Authors' contributions}

AF designed the study, carried out the field work, performed statistical analyses of molecular data, and drafted the manuscript. TP carried out the field work and analyzed morphological and echolocation data. TÖ carried out the field and molecular laboratory work. EÇ participated in the design of the study, carried out the field work and helped in drafting the manuscript. All authors read and approved the manuscript.

\section{Acknowledgements}

This work was supported by a grant (No. 09Y102P) from the Research Fund of Boğaziçi University in Istanbul. We would like to thank Raşit Bilgin for his comments on the manuscript and Prof Orhan Yenigün for his support.

\section{Author Details}

IInstitute of Environmental Sciences, Boğaziçi University, 34342 Istanbul, Turkey and 2 Institute of Systematics and Evolution of Animals, Polish Academy of Science, Sławkowska 17, 31-016 Kraków, Poland

Received: 14 December 2009 Accepted: 30 April 2010

Published: 30 April 2010

\section{References}

1. Bickford D, Lohman DJ, Sodhi NS, Ng PKL, Meier R, Winker K, Ingram KK, Das I: Cryptic species as a window on diversity and conservation. Trends Ecol Evol 2007, 22:148-155.

2. Baker RJ, Bradley RD: Speciation in mammals and the genetic species concept. J Mammal 2006, 87:643-662.

3. Jones G, Barlow KE: Cryptic species of echolocating bats. In Echolocation in Bats and Dolphins Edited by: Thomas JA, et al. University of Chicago Press; 2003:345-349

4. Ibanez C, Garcia-Mudarra JL, Ruedi M, Stadelmann B, Juste J: The Iberian contribution to cryptic diversity in European bats. Acta Chiropt 2006, 8:277-297

5. Mayer F, Dietz C, Kiefer A: Molecular species identification boosts bat diversity. Front Zool 2007, 4:4

6. Simmons NB: Order Chiroptera. In Mammal Species of the World: Taxonomic and Geographic Reference Edited by: Wilson DE, Reeder DM. Washington: Smithsonian Institution Press; 2005:312-529.

7. Appleton BR, McKenzie JA, Christidis L: Molecular systematics and biogeography of the bent-wing bat complex Miniopterus schreibersii (Kuhl, 1817) (Chiroptera: Vespertilionidae). Mol Phylogenet Evol 2004, 31:431-439.

8. Miller-Butterworth CM, Eick G, Jacobs DS, Schoeman MC, Harley EH: Genetic and phenotypic differences between South African longfingered bats, with a global Miniopterine phylogeny. J Mammal 2005 86:1121-1135 
9. Furman A, Öztunç T, Çoraman E: On the phylogeny of Miniopterus schreibersii schreibersii and Miniopterus schreibersii pallidus from Asia Minor in reference to other Miniopterus taxa (Chiroptera: Vespertilionidae). Acta Chiropt 2010, 12:61-72.

10. Hutson AM, Aulagnier S, Benda P, Karataş A, Palmeirim J, Paunović M: Miniopterus schreibersii. IUCN 2009. IUCN Red List of Threatened Species. Version 2009.12008 [http://www.iucnredlist.org]. downloaded on 1 November 2009

11. Bilgin R, Karataş A, Çoraman E, Disotell T, Morales JC: Regionally and climatically restricted patterns of distribution of genetic diversity in a migratory bat species, Miniopterus schreibersii (Chiroptera: Vespertilionidae). BMC Evol Biol 2008, 8:209.

12. Furman A, Çoraman E, Bilgin R, Karataş A: Molecular ecology and phylogeography of the bent-wing bat complex (Miniopterus schreibersii) (Chiroptera: Vespertilionidae) in Asia Minor and adjacent regions. Zool Scr 2009, 38:129-141.

13. Boye P: Miniopterus schreibersii Natterer in Kuhl, 1819 Langflügelfledermaus. In Handbuch der Säugetiere Europas. Fledertiere II Edited by: Krapp F. Wiesbaden Aula-Verlag; 2004:1093-1122.

14. Pereira MJR, Salqueiro P, Rodrigues L, Coelho MM, Palmeirim JM: Population structure of a cave-dwelling bat, Miniopterus schreibersii: does it reflect history and social organization? J Hered 2009, 100:533-544

15. Worthington Wilmer J, Barratt E: A non-lethal method of tissue sampling for genetic studies of chiropterans. Bat Res News 1996, 37:1-3.

16. Irwin DM, Kocher TD, Wilson AC: Evolution of the cytochrome $b$ gene of mammals. J Mol Evol 1991, 32:128-144.

17. Wilkinson GS, Chapman AM: Length and sequence variation in evening bat D-loop mtDNA. Genetics 1991, 128:607-617.

18. Thompson JD, Gibson TJ, Plewniak F, Jeanmougin F, Higgins DG: The CLUSTAL_X windows interface: flexible strategies for multiple sequence alignment aided by quality analysis tools. Nucleic Acids Res 1997, 25:4876-4882

19. Miller-Butterworth CM, Jacobs DS, Harley EH: Isolation and characterization of highly polymorphic microsatellite loci in Schreibers' long fingered bat, Miniopterus schreibersii (Chiroptera: Vespertilionidae). Mol Ecol Notes 2002, 2:139-141.

20. Han BY, Hua PY, Gu XM, Miller-Butterworth CM, Zhang SY: Isolation and characterization of microsatellite loci in the western long-fingered bat, Miniopterus magnater. Mol Ecol Notes 2008, 8:1445-1447.

21. Moore SS, Hale P, Byrne K: NCAM: a polymorphic microsatellite locus conserved across eutherian mammal species. Anim Genet 1998, 29:33-36.

22. van Oosterhout $C$, Hutchinson WF, Wills DP, Shipley P: MICROCHECKER: software for identifying and correcting genotyping errors in microsatellite data. Mol Ecol Notes 2004, 4:535-538.

23. Tajima F: Evolutionary relationship of DNA sequences in finite populations. Genetics 1983, 105:437-460.

24. Nei M: Molecular evolutionary genetics. New York Columbia University Press; 1987

25. Librado P, Rozas J: DnaSP v5: a software for comprehensive analysis of DNA polymorphism data. Bioinformatics 2009, 25:1451-1452.

26. Excoffier L, Laval G, Schneider S: Arlequin ver. 3.0: an integrated software package for population genetics data analysis. Evol Bioinform Online 2005, 1:47-50.

27. Jin L, Nei M: Limitations of the Evolutionary Parsimony Method of Phylogenetic Analysis. Mol Biol Evol 1990, 7:82-102.

28. Piry S, Alapetite A, Cornuet JM, Paetkau D, Baudouin L, Estoup A: GeneClass2: a software for genetic assignment and first-generation migrant detection. J Hered 2004, 95:536-539.

29. Rannala B, Mountain JL: Detecting immigration by using multilocus genotypes. Proc Nat/ Acad Sci USA 1997, 94:9197-9201.

30. Rousset F: Genetic differentiation and estimation of gene flow from Fstatistics under isolation by distance. Genetics 1997, 145:1219-1228.

31. Jensen JL, Bohonak AJ, Kelley ST: Isolation by distance, web service. BMC Genet 2005, 6:13.

32. Templeton AR, Crandall KA, Sing CF: A cladistic analysis of phenotypic associations with haplotypes inferred from restriction endonuclease mapping and DNA sequence data. III. Cladogram estimation. Genetics 1992, 132:619-633.

33. Clement M, Posada D, Crandall KA: TCS: a computer program to estimate gene genealogies. Mol Ecol 2000, 9:1657-1659.
34. Slatkin M, Hudson RR: Pairwise comparisons of mitochondrial DNA sequences in stable and exponentially growing populations. Genetics 1991, 129:555-562.

35. Rogers AR, Harpending H: Population growth makes waves in the distribution of pairwise genetic differences. Mol Biol Evol 1992, 9:552-569.

36. Petit E, Excoffier L, Mayer F: No evidence of bottleneck in the postglacial recolonization of Europe by the noctule bat (Nyctalus noctula). Evolution 1999, 53:1247-1258.

37. Nachman MW, Boyer SN, Searle JB, Aquadro CF: Mitochondrial DNA variation and the evolution of Robertsonian chromosomal races of house mice, Mus domesticus. Genetics 1994, 136:1105-1120.

38. Vigilant L, Stoneking M, Harpending H, Hawkes K, Wilson AC: African populations and the evolution of human mitochondrial DNA. Science 1991, 253:1503-1507.

39. Shapiro B, Drummond AJ, Rambaut A, Wilson MC, Matheus PE, Sher AV, Pybus OG, Gilbert MT, Barnes I, Binladen J, Willerslev E, Hansen AJ, Baryshnikov GF, Burns JA, Davydov S, Driver JC, Froese DG, Harington CR Keddie G, Kosintsev P, Kunz ML, Martin LD, Stephenson RO, Storer J, Tedford R, Zimov S, Cooper A: Rise and fall of the Beringian steppe bison. Science 2004, 306:1561-1565.

40. Saitou N, Nei M: The neighbour-joining method: a new method for reconstructing phylogenetics trees. Mol Biol Evol 1987, 4:406-425.

41. Ruedi M, McCracken GF: Genetics and evolution: Phylogeographic analysis of bats. In Ecological and behavioral methods for the study of bats Edited by: Kunz TH, Parsons S. Boston, Johns Hopkins University Press; 2009:739-756

42. Swofford DL: PAUP*. Phylogenetic Analysis Using Parsimony (and other methods) Sunderland Sinauer Associates; 2001.

43. Nei M, Tajima F, Tateno Y: Accuracy of estimated phylogenetic trees from molecular data. J Mol Evol 1983, 19:153-170.

44. Findley JS, Studier EH, Wilson DE: Morphological properties of bat wings. J Mammal 1972, 53:429-444.

45. Garcia-Mudarra JL, Ibanez C, Juste J: The Straits of Gibraltar: barrier or bridge to Ibero-Moroccan bat diversity? Biol J Linn Soc Lond 2009, 96:434-450

46. Nei M, Maruyama T, Chakraborty R: The bottleneck effect and genetic variability in populations. Evolution 1975, 29:1-10.

47. Ibrahim K, Nichols RA, Hewitt GM: Spatial patterns of genetic variation generated by different forms of dispersal during range expansion. Heredity 1996, 77:282-291.

48. Neuweiler G: Auditory adaptations for prey capture in echolocating bats. Physiol Rev 1990, 70:615-641.

49. Juste J, Ibàñez C, Muñoz J, Trujillo D, Benda P, Karatas A, Ruedi M: Mitochondrial phylogeography of the long-eared bats (Plecotus) in the Mediterranean Palaearctic and Atlantic Islands. Mol Phylogenet Evol 2004, 31:1114-1126.

50. Dietrich S, Szameitat DP, Kiefer A, Schnitzler HU, Denzinger A: Echolocation signals of the plecotine bat, Plecotus macrobullaris Kuzyakin, 1965. Acta Chiropt 2006, 8:465-475.

51. Furman A, Öztunç T, Postawa T, Çoraman E: Shallow genetic differentiation in Miniopterus schreibersii (Chiroptera: Vespertilionidae) indicates a relatively recent re-colonization of Europe from a single glacial refugium. Acta Chiropt 2010, 12:51-59.

52. Hardin G: The Competitive Exclusion Principle. Science 1960 131:1292-1297.

53. de Queiroz K: Species concepts and species delimitation. Syst Bio/ 2007, 56:879-886

54. Nixon KC, Wheeler QD: An amplification of the phylogenetic species concept. Cladistics 1990, 6:211-223.

55. Meier R, Willmann R: The Hennigian species concept. In Species concepts and phylogenetic theory Edited by: Wheeler QD, Meier R. New York: Columbia University Press; 2000:30-43.

56. Michener CD: Diverse approaches to systematics. Evol Biol 1970, 4:1-38.

57. Sneath PHA, Sokal RR: Numerical taxonomy: the principles and practice of numerical classification San Francisco W. H. Freeman; 1973.

58. Mayr E: Animal species and evolution Cambridge The Belnap Press of Harvard University; 1963.

59. Dobzhansky T: Genetics of the evolutionary process New York Columbia University Press; 1970

60. Bilgin R, Furman A, Çoraman E, Karataş A: Phylogeography of the Mediterranean horseshoe bat, Rhinolophus euryale (Chiroptera: 
Rhinolopoidae) in southeastern Europe and Anatolia. Acta Chiropt 2008, 10:41-49.

61. Bilgin R, Çoraman E, Karataş A, Morales JC: Phylogeography of the greater horseshoe bat, Rhinolophus ferrumequinum (Chiroptera: Rhinolophidae), in southeastern Europe and Anatolia, with a specific focus on whether the Sea of Marmara is a barrier to gene flow. Acta Chiropt 2009, 11:53-60.

doi: $10.1186 / 1471-2148-10-121$

Cite this article as: Furman et al., Cryptic diversity of the bent-wing bat, Miniopterus schreibersii (Chiroptera: Vespertilionidae), in Asia Minor BMC Evolutionary Biology 2010, 10:121

Submit your next manuscript to BioMed Centra and take full advantage of:

- Convenient online submission

- Thorough peer review

- No space constraints or color figure charges

- Immediate publication on acceptance

- Inclusion in PubMed, CAS, Scopus and Google Scholar

- Research which is freely available for redistribution

Submit your manuscript at www.biomedcentral.com/submit 